\title{
A!
}

This is an electronic reprint of the original article.

This reprint may differ from the original in pagination and typographic detail.

Maze, Ramia

\section{Bookmaking as Critical and Feminist Practice of Design}

\section{Published in:}

Proceedings of DRS2018

DOI:

10.21606/dma.2018.469

Published: 01/01/2018

Document Version

Publisher's PDF, also known as Version of record

Published under the following license:

CC BY-NC-SA

Please cite the original version:

Maze, R. (2018). Bookmaking as Critical and Feminist Practice of Design. In C. Storni, K. Leahy, M. McMahon, P. Lloyd, \& E. Bohemia (Eds.), Proceedings of DRS2018: Catalyst (Vol. 1, pp. 568-579). Design Research Society. https://doi.org/10.21606/dma.2018.469

This material is protected by copyright and other intellectual property rights, and duplication or sale of all or part of any of the repository collections is not permitted, except that material may be duplicated by you for your research use or educational purposes in electronic or print form. You must obtain permission for any other use. Electronic or print copies may not be offered, whether for sale or otherwise to anyone who is not an authorised user. 


\section{Bookmaking as Critical and Feminist Practice of Design}

MAZÉ Ramia

Aalto University, Finland

ramia.maze@aalto.fi

doi: 10.21606/dma.2018.469

Expansion of the arts in academia has called into question concepts, norms and regulations concerning writing and publishing. Given precedents of 'critical practices of design' and 'research through practice' grappling with such questions, I take these as ways to reconsider the academic activity of making a book ('bookmaking') as a critical and feminist practice of design. Through feminist modalities articulated by Jane Rendell - namely, collectivity, interiority, alterity, materiality, and performativity - I describe two edited books, through which I am able to discuss critical and feminist orientations in bookmaking practice. I argue that feminist practice critiques but also projects, activates, and enacts alternative norms or ideals - here, alternatives to academic norms concerning edited books. Naming and elucidating detailed aspects of bookmaking activity, as mundane critical 'practise' continually deliberated and performed, it is nevertheless possible to draw relations to larger theoretical issues. For example, discussing across differently situated/conditioned bookmaking practices makes it possible to trace implications of bookmaking within larger political economies, socio-economic structures, theoretical and ideological commitments.

critical practices of design, feminist theory research through practice, book and bookmaking, editing

\section{Introduction}

The expansion of the arts in higher education, research and academia has surfaced vivid discussions for many decades, for example concerning the role of arts practices in theory-building and knowledge-making. Relations, interactions and interdependencies of theory and practice have been central to both discussions of 'critical practices of design' and 'research through practice' (Mazé \& Redström, 2009). New and hybrid conceptions have emerged particularly via socio-technical and feminist studies, for example through concepts explored by Donna Haraway (1988, "situated knowledges"; 2011, cats' cradles and "string figures are thinking as well as making practices, pedagogical practices and cosmological performances") and contemporary crossovers into design such as Janet Jeffries (2012, "mangling practices"), Kristina Lindström and Åsa Ståhl (2014, "patchworking ways of knowing") and Laura Forlano (2017, "data rituals"). Actively engaging with 
such concepts such as knowledge, knowing, thinking and data, the arts have also interrogated the institutionalized forms that practices of theorization takes, including norms and regulations of documenting, writing, evaluating and publishing practices. As architectural theorist and feminist scholar Jane Rendell articulates:

The rise in what has been termed practice-led/-based research... has produced an understanding of practice as a process which occurs not only through the design of building but also through the activities of using, occupying and experiencing them, and through the mode of writing and imaging used to describe, analyse and interrogate them. (Rendell, 2011, p. 23)

The doctoral dissertation has been a site for such critique in design. It was in my own dissertation that I encountered, questioned and reconfigured structural, material and graphical qualities of the book itself to better reflect particular qualities of knowledge-making advanced within (Mazé, 2007). This and other creative and critical interrogation of the dissertation form by teachers, colleagues, peers and students, have, in turn, been the subject of studies by others (Seago \& Dunne, 1999; Yee, 2010; Krogh et al, 2015). Further and dramatic examples are found within dissertations in more established academic disciplines such as architecture (c.f. Grillner, 2000; Bonnevier, 2007; Burroughs, 2016) that, informed by feminist writing practices (Livholts, 2011), articulate and explore alternative subject/author positions, identities and voices, playing with and blurring theory/practice and high/low literary forms and boundaries.

While a dissertation is typically an individual and mono-disciplinary work (with notable exceptions f.ex. Lindström \& Ståhl, 2014), edited books and anthologies entail further interrogation of these issues as they include contributions of multiple authors and potentially multiple disciplines, in which multiplying norms and regulations are even more challenging and, potentially, a critique even more radical. Given precedents in the form of dissertations as well as of other forms of practice by those self-identified in design as 'critical' and/or 'feminist', I argue here that making a book can be understood as a critical and feminist practice of design. This is introduced by sketching some preoccupations of critical design/architecture with the material object but, also, beyond the object, and $I$ argue that expanded forms of critical practices include activities such as lecturing and administering as well as writing, reviewing, editing, i.e., 'bookmaking'.

Bookmaking is a term associated with gambling, its speculative and sometimes shady methods of 'adjusting the odds'. I use the term here as feminist wordplay (Livholts, 2011; Haraway, 2011) and in reference to the risks that such practices can and must take to "trouble" (Stengers \& Despret, 2014) norms. Similarly, architect and theorist Stan Allen elaborates his use of the term 'speculative':

It is important to clarify what I mean here by 'theoretical' or 'experimental' work. I don't mean maintaining a safe, academic distance from the messy complexity complexities of practice, program, politics and reality. (I prefer the term speculative not only for its etymological connection with seeing but also for its slightly sleazy real estate connotation). (Allen, 1993, p. 100)

I focus on specifically feminist approaches to critical practice through Rendell (2011), elaborating upon two edited books through which I am able to discuss critical dimensions and feminist positions in the detailed everyday activities of bookmaking.

\subsection{Research through (bookmaking) practice}

Acknowledging and taking advantage of my own particular and situated knowledge on the topic, I consider this paper in the vein of 'research through practice'. In this vein, my work reported here can be understood as a kind of 'practice-led' research, in which my reflections and conceptualizations have accumulated gradually on the bases of multiple experience of bookmaking. Specifically, I have been an author, reviewer and editor in the two books described: Share This Book (Mazé, Plöjel, Olausson, Redström \& Zetterlund, 2013) and Feminist Futures of Spatial Practice (Schalk, 
Kristiansson \& Mazé, 2017). Thus, cumulatively and retrospectively theorized, my argument here can be understood as reflection 'on' and 'after' rather than 'in' practice (Blythe \& van Schaik, 2013). Through doing book projects and encountering other personal, disciplinary and institutional standpoints, my own reflexivity has sharpened as a sort of moving between 'inside' and 'outside' perspectives on the practice (Mazé, 2009). The occasion of the latest book, Feminist Futures, has occasioned a more explicit, externalized and systematic reflection on editing and producing the book as a critical practice, and is also therefore more extensively elaborated here.

\section{Critical and Feminist Practices of Design}

By 'critical practices of design', I refer to various critical movements within architecture, design, and the applied arts (Mazé, 2007; Mazé \& Redström, 2009). Materiality has been the predominant intersecting issue for critical practices of design and of architecture. Each has explored the form of critique - the spatial and material form in which critical practice manifests. Early critical architecture was preoccupied by form and the semiotics and transmission of theories and ideologies through form (Mazé, 2007), which are in some ways echo in Dunne's articulation of 'objects as discourse' (Dunne, 1989). In Dunne's doctoral dissertation that included both written and design components:

The electronic objects produced in the studio section of his doctorate are still 'design,' but in the sense of a 'material thesis' in which the object itself becomes a physical critique... research is interpreted as 'conceptual modelling' involving a critique of existing approaches to production/consumption communicated through highly considered artifacts. (Seago \& Dunne, 1999 p. 12)

Preoccupation with materiality, objects and artifacts has provoked varied responses, and myself and others have instead articulated roles of critical object in consumption practices (Mazé, 2013), in discursive processes with industry (Tharp \& Tharp, 2013), in the formation of publics (Kerridge, 2015), and in social media (Morrison et al., 2011). As critical practices and 'research through practice' have thus expanded 'beyond the object' in and of itself, its increasingly necessary to engage with social and critical social theories to deepen design research (Mazé \& Redström, 2009).

\subsection{Critical practices of design 'beyond the object'}

In critical graphic design discourses, the structures and activities circumscribing artifacts are highlighted and not only the graphical form. An example is Dexter Sinister, which started as a selfreflexive response in the wake of 9/11 by David Reinfurt and Stuart Bailey (Reinfurt, 2009). Their work can be discussed in formal terms - they do produce books. But their practice also takes the form of the 'Just-In-Time Workshop \& Occasional Bookstore', a space and time for anyone to learn and self-produce graphic design and with a lending-library and community-building intent. This alternative production and distribution model is a critique of material economic and even social unsustainability of their discipline - "best described as a self-conscious model: both a regular design studio and a tool to question the nature of a design studio" (Dexter Sinister, 2009, p. 267).

Similarly emphasizing the 'practice' rather than the object in and of itself, James Goggin's firm is named Practise, in which the British spelling with an ' $s$ ' exclusively denotes a verb (whereas 'practice' can be a noun or a verb). Goggin positions his work in relation to both critical and 'relational' (as in "relational aesthetics") in design to expand a notion of criticality as inherent and intentional within everyday work and social activities:

My own graphic design practice is largely organizational, in both performative and pragmatic senses: lecturing, workshops, curating, but also editing, production, distribution. Graphic designers often complain that, realistically, in a professional practice one spends only a small fraction of time actually 'designing', the rest being taken up with so-called 'admin' (that is, organizing): phone calls, reading, meeting clients, press-passing, making mock-ups, etc. (Practise \& Europa, 2009, pp. 43-45) 
The experienced graphic designer - whether working only by commission, or with a mix of commissioned and self-initiated projects - becomes naturally skilled in all of these areas, so it becomes logical to apply this knowledge both to the service of a client and as a means of self-production, analysing all channels of interpretation, production and distribution for potential creative and critical scope. (Goggin, 2011, p. 33)

Practice or 'practise' could thus be understood as a further intersection between genres of critical design and architecture "beyond the object" (Mazé, 2007). Such a commitment is shared in contemporary conceptions of "critical spatial practice" articulated by Jane Rendell. She emphasizes 'practice' given both the silos within the architectural academy and contemporary societal issues. In the vein of critical social and feminist theories, she articulates theory and practice as inevitably conditioned by and therefore taking a position in relation to larger societal structures and injustices. This requires understanding, but also action and resistance, and it is practice and everyday activities that foregrounds both creativity as well as critique (Rendell, 2011).

Rendell's articulation of critical spatial practice is an analysis of architecture, including the material, social and organizational practices of architects, firms and collectives. Further, she extends the notion to her own everyday practices, including those of lecturing, writing and editing. For her, these are critical and spatial practices - since creative and critical knowledge-making within these cannot be separated from processes and experiences of architecture (Rendell, 2005, 2007a, 2007b).

\subsection{Critical feminist practices}

In terms of this additional discursive intersection between accounts of critical practices of design and architecture, everyday embodied, social and spatial aspects come into focus. Critical graphic designers perceive their practice (as noun and verb) as critical, not only the objects produced therein. The way something is produced and distributed, the researching of a brief, the writing of a contract or budget, the social interactions, the writing and editing of a book - these can also be treated as critical design/spatial practices. This opens new areas of inquiry, such as how a critique is performed by subjects (by and for whom) within particular activities (how, i.e. modes of operation and organization).

Rendell sharpens articulations in relation to questions such as who and how. Through a feminist lens, she analyses critical spatial practices in more particular terms, in terms of "the subject matters that resonate with feminists as well as modes of operation that feature strongly in a predominantly feminist mode of critical spatial practice" (Rendell, 2011, p. 24). These modes of operation are material and spatial but also characterized by forms of social relation, order and structure, as well as relation to oneself, subjectivity, identity and voice. Rendell names feminist modes including: collectivity, interiority, alterity, materiality, and performativity.

- Collectivity in Rendell's account represents not only a particular organizational form of practice (she points to several feminist architectural collectives including FATALE, in which my Feminist Futures co-editor Meike Schalk was an initiator) but also a focus and direction of practice. "In architecture, to position a building as a 'methodology', rather than as the end result of the method or process that makes the building is a radical proposition" (Rendell, 2011 , p. 26). She thus makes a connection between critical spatial practice and relational aesthetics and practices in the arts, via feminist philosophical and ideological commitments.

- She traces interiority to a shift brought about by philosophies of deconstruction that refute binary and hierarchical conceptions of 'either/or' and, instead, elaborate on 'both/and'. Instead of 'public' or 'private', 'external' or 'internal', 'male' or 'female', spectrums, hybrids and alternatives in spatial, embodied and socio-political terms can be explored and valorized. In feminist approaches this can manifest as exploration of the connectedness and interdependency of psychic and societal conditions, domestic and political economies, cultural and ecological systems. 
- $\quad$ Alterity relates to discussions of location over several decades, for example in feminist discussions of 'situated knowledge and 'standpoint theory' to examine inter-relation between location, identity and knowledge not only in a geographic but an epistemological sense. Tracing relations to post-colonial theory, Rendell discusses examples that, from alternative or sub-altern positions redefine hegemonic practices such as historiography. Potentially vulnerable practitioners may take on guises, such as Shia women writers under a Taliban regime meeting as sewing circles.

- As performative, she articulates the exploration of one's relation to another, for example relations between differently-situated knowledges. She is interested in the movement itself, moving outside of and coming back to one's own discipline in another way. In feminist writing traditions she discusses how moving between authorial voices and literary genres inquire into writers' relations to their own work and challenge the possibility of any singular and static point of view. Besides voice and genre, she notes the spatial and material qualities of a text, "the critical, interdisciplinary and performative qualities of writing, as a form of materialized philosophy" (Rendell, 2011, p. 37).

In this section, I have expanded the terms of critical practices of design in this section and thereafter honed in upon some more particularly feminist critical lenses. Next, I will reflect upon this in action by accounting for my own everyday activities as critical and feminist, specifically activities within my practice as a design researcher including lecturing, writing, reviewing and editing, etc. More specifically, in order to understand the 'how' and 'who' as well as the material/spatial aspects of these, I will use Rendell's modes to discuss these as critical feminist practices of design.

\section{Bookmaking as critical (feminist) practices of design}

Rendell argues that the edited book is an ideal site for investigating critical and spatial movements between disciplines, in her case between spatial and historical knowledge, theory and history (Rendell, 2007). This idea was enacted physically and socially in the 2009 FATALE Salon 'Anthology Works', in which Rendell was a keynote. Participants including myself took part in a series of activities exploring the notion of 'anthology' from different disciplinary positions. An example was Katja Grillner's activity 'Architecture Writing Workshop', previously enacted with Mona Livholts and others (Grillner, 2013), that unfolded as role-play and dialog among participants through the medium of extracted quotations from a historical canon of feminist texts.

Not only the content of the texts but the format of the activity itself was positioned as feminist - as practicing the conventional academic anthology "otherhow" or "otherwise" (Petrescu, 2007). The anthology as a structure for selecting, giving voice to and citing particular texts and authors, can become feminist or decolonial when done by or with others, and otherwise. Anthologizing and other academic practices have normativities and exclusions - another such academically institutionalized practice is citation, prompting Sara Ahmed's call for 'critical citational practices':

The reproduction of a discipline can be the reproduction of these techniques of selection, ways of making certain bodies and thematics core to the discipline, and others not even part. (Ahmed, 2012)

In Anthology Works, as any anthology, texts were selected and sequenced, but here collectively and performatively, in an embodied and dialogic way creating relations or interiority among differentlysituated knowledges, and in which sub-altern authors outside of the mainstream canon were voiced and heard by each and all together. Anthology Works is a microcosm of two examples of books, or bookmaking practices, that I elaborate below. In the words of Dexter Sinister, these are both academic edited books and tools to question the nature of an academic edited book. In other terms:

Feminist futures are becoming when common projects - e.g. a course, a conference, an exhibition, a carnival, a series of 'rehearsals', etc. - not only momentarily produce an alternative space, but effect new connections and social relations that can alter 
ingrained patriarchal structures as many of us still experience them, i.e. in hierarchical and competitive educational systems and disciplinary structures (see Stengers and Despret, 2014; and Ahmed, 2012). (Schalk, Mazé, Kristiansson \& Fanni, 2017)

\subsection{Bookmaking: Share this Book}

Share this Book (Mazé et al, 2013) is a co-authored and co-edited book produced during a design research project setup to articulate critical perspectives on contemporary sustainable design from three perspectives, from that of design theory (through the perspective of Johan Redström), history (through that of Christina Zetterlund) and a practitioner (in this case, my own accounts of 'research through practice'). The book included sections authored by each, an introduction that included a jointly-authored part (expressed as "we") and individually-authored parts (indicated by names), and a concluding transcript of a dialog among the three and the book designer Matilda Plöjel. Instead of producing an exhibition or prototype, as might be typical in critical design or 'research through design', the book was setup as a kind of exhibit. Each authored section also included pages given over a previously or newly created collaborative work external to the project. Importantly, this was not positioned as illustration but as performance of the argument through other means, whether photography, curation or cultural production.

The book designer was present (and paid) from the start as member of the book team, and she designed a unique typeface as well as analysed, proposed and made choices regarding printing, paper, binding, protective cover, etc., all from a staunch sustainability perspective (Borggren et al., 2011). Beyond the ecological footprint of the printed book, she considered distribution and circulation, which led to a fourth 'exhibit' in the book with an external collaborator, a visualtypographic essay about sharing, reusing, recycling, etc., the book - hence the title Share This Book and its cover as start of the exhibit. Her investigation drove priorities within negotiations with publishers, and we left several publishing options due to their unsustainable production and distribution typical in the industry. The book was unconventionally printed, bound and distributed, including a second edition (with own ISBN) in digital form. These choices were elaborated in an 'extended colophon' that had the import of a chapter in size and in the Table of Contents.

The example of this book deconstructs everyday activities in the practice of 'bookmaking' that can be seen, and in this case, were intended, to have a 'critical scope' (to borrow the words of Goggin). As a basis for discussion across two books in the last section of this paper, three relevant aspects (among others) of activities and decisions with critical import include:

- Selection, positioning, sequencing and voices of individual contributors

- Treatment and relation of theoretical and practical work (both labor and content ie. 'exhibits')

- Terms, materiality and ownership within industrial production and distribution

\subsection{Bookmaking: Feminist Futures of Spatial Practice}

This book was the culmination of a process set into motion in 2011. At that time, a course themed 'Feminist Futures' was organized as part of the 'Introduction to Architecture and Gender' module offered since 2008 by the Critical Studies unit of Royal Institute of Technology (KTH) School of Architecture in Stockholm, Sweden. In 2011, the course was a collaboration with the organizations Women in Swedish Performing Arts (WISP) and The New Beauty Council. Organized as a series of lectures and workshops for students and the public, the course became a platform for interaction among a local network and international contributors from architecture, the arts and other fields. The course was a stage for testing various feminist scenarios and subject positions, which prompted the initiation of a process developing the book to articulate different and common perspectives. The process of producing as well as the production of the book can be understood as a feminist critical practice (or "pedagogical queering-tool" (Schalk et al, 2017) in many ways. One aspect is the setup of the course itself. Meike Schalk from FATALE and KTH and Thérèse Kristiansson from The New Beauty Council organized the course in particular ways that defined a creative as well as 
resistant relation to the normal procedures, regulations and expectations of an academic course. It had an open admissions policy regarding academic level and university registration status of potential participants, and it was also open to the public. The venue was off-campus at WISP. These and other careful micro-decisions were debated from feminist and queer standpoints throughout the activity of planning and organizing the course. These produced a course with a very diverse range of participants (from 20- to 70-year olds), scholars as well as practitioners spanning an unusually wide range of disciplines.

Many further aspects of the course as feminist critical practice could be discussed. This ranges from the selection and handling of contributors and contributions, the selection and involvement of the book's graphic designer, the making and use of typeface ("Lipstick" by graphic designer Kerstin Hanson), the negotiation of copyright and publisher's logotype placement, etc. Here, and in the 'research through practice' tradition of acknowledging my own particular 'situated knowledge', I will account for three aspects that I experienced directly that raise relevant issues regarding the book as (feminist) critical design practice.

\subsubsection{Lecturing and authoring in dialog}

The series consisted of ten sessions, one afternoon per week, each with a lecture and workshop... The workshops were an important pedagogical foundation, enabling experiential and embodied engagement with the lecture content. Workshops included various making activities, for example, collages, drawings, models, doing crafts, explicitly full-bodied as well as reflective activities, such as writing individually and together, and performances of various kinds. During the course, these experiences of 'learning through doing', or practicing 'otherhow', became increasingly important... Through such activities, we found diverse ways of learning and expressing through our own experiences as well as for discussing and collaborating with others.

(Schalk, Mazé, Kristiansson \& Fanni, 2017, p. 17)

Along the lines of Rendell's critical spatial practice, the course enacted particular learning and teaching experiences, in which multiple forms of knowledge-making were actively performed towards a particular (normative, feminist) end. As one of the invited contributors with colleague Josefin Wangel, we extended the dialogical principle as one between theory and practice within our respective fields of design and futures studies. Josefin and I prepared a lecture and guiding slides, in which we took turns, each outlining key issues and (feminist) alternatives, in theoretical terms, in terms of others' practices and with an example of our own practices. In the process of preparing and in delivering the lecture itself, we continually re-negotiated the selection, articulation and relevance of each of these aspects in relation to the other. This was the first public version of an informal dialog begun in the coffee break of the Stockholm Futures Conference where we were speaking individually. Within our session workshop, we formulated a scenario activity for participants to envision the future from an embodied and socio-material perspective, ie. their desired future societal structure and material culture. In this, further positions were articulated within the dialog.

We transformed our dialog in another form when the book development commenced and we were invited to contribute. Our writing process for the chapter evolved in the form of a dialog in three voices - in sections authored individually and co-authored as "we". These voices were interwoven as disciplinarily- and personally-grounded angles on three shared issues of concern. In this, we extended the dialogical principle from a teaching format to a learning format for ourselves and from the course participants (who formulated other angles through the workshop), to an experiment within a tradition of feminist writing practices. Such writers refuse the colonial "God trick" (a single point of view imposed as neutral and universal; Harding, 2011) by carefully articulating the subjectivity, situated-ness and contingency of standpoints by attending to issues of voice, identity and position within authorship. 


\subsubsection{Reviewing and editing in the round}

Five 'roundtable' sessions were organized between May and August 2014 by Meike and Thérèse. Some roundtables took place at the Swedish Centre for Architecture and Design (Ark-Des), some at a local studio, and one at the Institute for Housing and Urban Research in Uppsala invited by Irene Molina. Contributors to the course in 2011 and previous years were asked to develop texts and projects for this book. Roundtables took the form of intimate conversations of texts circulated in advance, closely read and carefully commented by participants and a designated 'peer reviewer'.

(Schalk, Mazé, Kristiansson \& Fanni, 2017 p. 18)

As contributing authors, Josefin and I were invited to a roundtable. This was a new concept - peer review 'in the round', in which contributors from different backgrounds, disciplines and different positions within the academic system or from outside met on equal grounds. Peer review is a key mechanism to ensure quality in the academic system in which many of us work. Instead of the standard 'blind' peer review, which serves gender and other measures of equality in publishing (not unequivocally), another approach was taken to 'quality' and 'equality' from feminist pedagogy, including "the pleasure of conversation" and "feminist collective reconstructions" (Petrescu, 2007). Each contributor had shared with all a chapter draft, which meant each was equally vulnerable and gave each a common stake in both receiving and giving feedback. Giving and receiving feedback in person, as a conversation and around a table entailed that critique became dialogic and mutualistic, articulated from distinctly different but mutually respectful positions. The external 'peer reviewer' in our session acted as kind of moderator, rather than as an evaluator, reading between the lines of the draft and listening for emerging issues in the conversation to highlight particular contributions and articulate common issues from the different perspectives.

Review had a pedagogical purpose as a kind of peer learning, in contrast to other purposes such as critique or evaluation. Unexpected commonalities and differences emerged within the peer review conversations, which thus constituted a kind of interpersonal or collective knowledge-making. After the roundtables, each draft further evolved through several cycles of further review with the three book editors. Reviewing continued as an increasingly precise form of dialog, in which each draft was discussed to articulate the main issues but then feedback was given in the form of two or three reviews unfolding each issue in different ways and from different perspectives. As editors also contributed with chapters, thus reviewed by the others, they were continually sensitive to the personal and power relations enacted within review processes. This reflection and transparency throughout the process attuned not only to articulating but listening carefully, more than in standard review or editorial processes. An implication is more careful and multifaceted editorial position, and the evolution of chapters that ever-more precisely in argument, language and form expressed the author(s) own position and voice.

\subsubsection{Differentiating and commoning styles}

Just as standard academic peer-review, editorial standards and style guides have their normativities and exclusions, we can recognize our own as we reproduce these or produce others. We have also learned by doing, through continual forms of dialogue, about our differences as well as our commonalities.

(Schalk, Mazé, Kristiansson \& Fanni, 2017, p. 22)

Already within cycles of review and revision of chapters, style guides began to loom large as critical, as a matter of authorial expression, disciplinary specificity, and representation of sources. This was also, of course, an issue of budget, workload and editorial standards. As contributing authors spanned disciplines and countries, there were differences in choice of British or American English, in choice of style guiding grammar, spelling and punctuation, convention for citation and bibliography, handling of imagery, permissions and captions. It is typically an editorial task to set and enforce a single standard and style throughout, which in turn is usually dictated by the choice of publisher. 
During the review process, and negotiations with publishers were still ongoing, editors made the choice not to make the decision based on anticipation or solicitation of a particular publisher. Instead, they encountered and discussed the issue within the context of each chapter, including diverse styles of argumentation and writing reflecting different positions, backgrounds and disciplinary conventions. Further, as many chapters experimented with feminist writing traditions or took unconventional forms such as dialog, interview, and visual essay, in which the choice of style was also a matter of self-expression and knowledge-making processes.

The first decision, then, was that author(s) of each contributing chapter should select their own style guide. This entailed that they had the main knowledge and responsibility concerning the style guide, as neither we editors nor copyeditors could know the full range of styles used across the chapters. This decision based on principle had consequences in additional revision cycles for author(s) to handle this themselves, extended timelines for copyediting, graphic design and, eventually, printing. For them, the variation of style is a direct expression of the interdisciplinarity of the book contents. A second decision was made concerning the bibliography based on commonality - rather than individual or disciplinary specificity. Unconventionally, the chapters do not end with a bibliography but, rather, all references are collected in a single style-guide standard at the end of the book and spanning 14 small-font, double-column pages. This decision entailed six extra work days by the editors. The consolidated references, however, end the book with a common form and, more importantly discovered in the process, reveal not only the breadth of references but also repeated and thus core sources shared across many authors, chapters and disciplines.

\section{Discussion and conclusion}

If Anthology Works elucidates bookmaking an anthology "otherhow" and "otherwise" (Petrescu, 2007), Share This Book and Feminist Futures of Design Practice further elaborate critical dimensions and feminist positions in the detailed everyday activities of bookmaking. Regarding Share This Book, I laid out above some aspects of such activities within bookmaking practice:

- Selection, positioning, sequencing and voices of individual contributors

- Treatment and relation of theoretical and practical work (both labor and content, i.e. 'exhibits')

- Terms, materiality and ownership within industrial production and distribution

Further, regarding Feminist Futures, and given the feminist subject matter of, such aspects of bookmaking practice are particularly relevant to query in terms of Rendell's modes collectivity, interiority, alterity, materiality, and performativity. While critical practices may generally examine how a particular social-spatial order is constructed, and critical spatial practice may work to destabilize that order, feminist practice is normative (Mazé, 2013). Feminist practice questions and opposes a given dominant/oppressive norm - it also projects, activates, and enacts alternative norms or ideals (Schalk, Mazé, Kristiansson \& Fanni, 2017). Feminist practices of design query not only the what (objects) and how (practice or 'practise') but the who, i.e. the subjectivities, positionalities and locations (that are often tacit or oppressed, see Prado, 2014).

In bookmaking Feminist Futures, collectivity was engaged in a variety of ways. In lecturing, authoring, and reviewing, personal and professional standpoints were carefully and continually re-positioned. In Share This Book, the different disciplinary standpoints were held apart - there were few sections written as "we", and the different textual and 'exhibit' components were carefully authored particularly to explore 'inside' and 'outside' perspectives on one's own and other's contributions (Mazé, 2009). In Feminist Futures, regarding style guides and citations, there was a similar clear demarcation of difference (each chapter with own style) and common canon (in the form of all references collected alphabetically at the end, with all names spelled out to also celebrate the toooften sub-altern gender/culture representation in citations). 
In the Feminist Futures chapter, voices were woven more intimately together in close dialog, a kind of interiority as mutual vulnerability through which identity, family and community dimensions as well as disciplinary perspectives could be unfolded. Similarly, in the roundtables, participants from distant social/cultural locations were present as a kind of alterity with a danger of inequality or hierarchy (or the sub-altern). However, the performative experience of face-to-face conversation, the vulnerability and responsibility of reviews to/from all, and the diplomatic moderation of the peer reviewer. There was never a 'universal' nor neutral position but, rather a safe space created spatially (in the classroom, around the table, and, consequently continued in more distant and written exchanges during editorial review). Indeed, the documentation is quite careful even about the mention of "making tea" that evokes Meike's feminine ethics of care.

In terms of treatment and relation of theoretical and practical work, each book had different approaches. In Share This Book and, to a lesser extent in Feminist Futures, contents, labor and time participants was carefully managed, including resource allocation for non-salaried participants. Perhaps Share This Book operated more of an 'or' than an 'and' logic, in which interiority in the form of participating researchers can be contrasted to others in the process, each operating perhaps more individually than collectively. Textual and 'exhibit' components were held apart through the distribution of parts within and across chapters, and through carefully differentiated voices and disciplinary standpoints. Nevertheless, the clear-cut terms also made it clear when boundaries were crossed, for example with the growing engagement of the graphic designer beyond the material to a clearly critical practice orientation along the way. In this way, potentially different treatment of participants or alterity of the designer or of practice as secondary or sub-altern in relation to theory shifted in a positive way over time, eventually manifesting in contributions with the designer's eventual status of a chapter and 'exhibit' in the Table of Contents.

In some ways, the handling of labor in Share This Book avoided the sometimes hidden inequalities of feminist collectivity (c.f. Berglund, 2007). At the same time, in Feminist Futures, with the particular attention to individual contributors, different voices, standpoints and styles, the labor in reviewing and editing could not be easily (nor desirably) anticipated. The issue of styles and common citations was arrived at performatively (and a bit painfully) through discussion of alternative (and feminist) approaches, and the principle was more important than labor/budget logics. Indeed Feminist Futures can perhaps elucidate the difficult dynamics of feminist economies (Gibson-Graham, 2008). It demonstrates a valuation and reliance on relationships and resources within a collectivity that evade the rationalities (and, perhaps in some cases, efficiencies and equalities at least in measurable terms) of market economic logics. Within bookmaking, there was no clear-cut either/or, but a continual interiority of re-negotiation among those with different conditions and concerns.

Regarding terms and ownership within industrial production and distribution, the two books are also distinctly different. Principle guided decisions performatively in Share This Book as incremental and continuous decisions concerning selection of publisher, printing materials, production and distribution methods. Certain norms (ie. sustainable) were held over others perhaps more conventionally held (ie. profit through mass-production/distribution, etc.) selection of publisher, printing inks and papers, production and distribution methods. In this sense, a quality of interiority, or internal logics, was also manifest across different procedures and externally. In Feminist Futures, the intense collectivity (of continual 'being-in-relation') and interiority (both/and, always) continuously performed, entailed more difficulties in drawing boundaries and endings. Principled and internally-shared commitments were sometimes difficult to reconcile with other structures and conditions such as the publisher's conventions and regulations. In retrospect, it is interesting to consider the copyright terms of each - Share This Book is Creative Commons while or difficulty to define individual as well as share terms in Feminist Futures has recently ended in a domineering and dead-end reprint negotiation on behalf of the publisher with a global partner. 


\subsection{Conclusion}

I do not propose here a potentially generalizable framework nor universal prescriptions - rather, and in the vein of 'research through practice', I would articulate my conclusions as a kind of delimited regime of situated and provisional knowledge (Brandt et al., 2011). Firstly, articulating critical design/architecture beyond the object, I have elaborated further intersections between - specifically, practice - and have extended and applied particularly feminist modes of bookmaking as a critical practice of design. Through the two examples, it becomes possible to distinguish normal and multiple other ways of doing bookmaking - indeed, this also helps to understand that notions such as collectivity can be understood, organized and experienced in many ways. Naming and elucidating detailed aspects of bookmaking activity, as mundane critical 'practise' continually deliberated and performed, it is nevertheless possible to draw relations to larger theoretical issues, for example in relation to Rendell's feminist modes that allow for clarification and differentiation across differently situated/conditioned bookmaking practices and larger socio-economic concepts and structures. As situated and provisional, this backdrop, bookmaking activities and feminist modes constitute a set of tools that I will further explore in my own work, and that may be interrogated by other critical/feminist practitioners on their own terms.

Acknowledgements: Share this Book was produced in a research project (number 20082257) funded by the Swedish Research Council VR and led by Johan Redström, to whom I'm grateful to along with Christina Zetterlund, Matilda Plöjel, Magnus Ericson, Lisa Olausson and Axl Books publisher Staffan Lundgren. Feminist Futures was funded with support from the Swedish Research Council Formas through the Strong Research Environment 'Architecture in Effect' and published by AADR/Spurbuchverlag, Rochus Hinkel. It's been a pleasure and privilege to collaborate with Meike Schalk, Thérèse Kristiansson, Josefin Wangel, and all authors and reviewers contributing to Feminist Futures.

\section{References}

Ahmed, Sara (2012). On Being Included: Racism and diversity in institutional life. Durham, NC: Duke University. Allen, S. (1993). Its Exercise, Under Certain Conditions. Columbia Documents of Architecture \& Theory, 89-113. Berglund, E. (2007). Doing Things Differently: Women's Design Service at 20. London: Women's Design Service Blythe, R., and van Schaik, L. (2013) What if Design Practice Matters?. In M. Fraser (Ed), Design Research in Architecture, pp. 53-69. London: Ashgate.

Bonnevier, K. (2007). Behind Straight Curtains: Towards a queer feminist theory of architecture. PhD Diss, KTH Royal Institute of Technology. Stockholm: Axl Books.

Borggren, C., Moberg, Å, \& Finnveden, G. (2011). Environmental impacts of paper books sold in traditional and internet bookshops. International Journal of Life Cycle Assessment 16, 138-147.

Brandt, E., Redström, J., Agger Eriksen, M., Binder, T. (2011). XLAB. Copenhagen: The Danish School Press.

Burroughs, B. (2016) Architectural Flirtations: A love storey. PhD Diss, KTH Royal Institute of Technology. Stockholm: Arkitektur- och designcentrum.

Dexter Sinister (2009). On Self-Initiated Projects as an Alternative Platform. In M. Ericson et al. (Eds), Iaspis Forum on Design and Critical Practice - The reader, pp. 265-294. Berlin: Sternberg Press / laspis.

Forlano, L. (2017). Data Rituals in Intimate Infrastructures: Crip Time and the Disabled Cyborg Body as an Epistemic Site of Feminist Science. Catalyst. Special Issue on Science out of Feminist Theory.

Gibson-Graham, J.K. (2008). Diverse Economies: Performative practices for "Other Worlds". Progress in Human Geography 32 (5), 613-632.

Goggin, J. (2011). Practice from Everyday Life. In A. Blauvelt, A. \& E. Lupton (Eds.), Graphic Design: Now in production, pp. 32-40. Minneapolis: Walker Art Center.

Grillner, K. (2013). Design Research and Critical Transformations: Situating though, projecting action. In M. Fraser (Ed), Design Research in Architecture, pp. 71-94. London: Ashgate.

Grillner, K., (2000). Ramble, Linger, and Gaze. PhD Diss, KTH Royal Institute of Technology, Stockholm, SE.

Haraway, D. (1988). Situated Knowledges: The science question in feminism and the privilege of partial perspective, Feminist Studies 14 (3), pp. 575-599.

Haraway, D. (2011). Science Fiction, Speculative Fabulation, String Figures, So Far. Acceptance speech for Pilgrim Award, July 7, 280.

Harding, S. (2011). The Postcolonial Science and Technology Studies Reader. Durham, US: Duke University. 
Hays, K. M. (1984). Critical Architecture: Between culture and form. Perspecta 21: 4-29.

Jeffries, J. (2012). Mangling Practices, in M. Mäkelä (Ed), Art of Research II, pp. 32-51. Helsinki: UIAH.

Kerridge, T. (2015). Designing Debate. PhD Diss., Goldsmiths University of London, UK.

Krogh, P.G., Markussen, T., and Bang, A.L. (2015). Ways of Drifting: 5 Methods of experimentation in research through design. In Proceedings of ICORD Research into Design Across Boundaries, Bangalore, IN.

Lindström, K., and Ståhl, Å. (2014) Patchworking Publics-in-the-making, PhD diss, Malmö University, Sweden. Livholts, Mona (Ed.) (2011) Emergent Writing Methodologies in Feminist Studies. London: Routledge.

Mazé, R, Plöjel, M., Olausson, L., Redström, J., and Zetterlund, C. (Eds)(2013). Share This Book: Critical perspectives and dialogues about design and sustainability. Stockholm: Axl Books,.

Mazé, R. (2007). Occupying Time: Design, technology, and the form of interaction. PhD diss, Malmö University and Blekinge Institute of Technology. Sweden. Stockholm: Axl Books.

Mazé, R. (2009). Critical of What? / Kritiska mot vad?. In M. Ericson et al. (Eds), laspis Forum on Design and Critical Practice - The reader, pp. 378-398. Berlin: Sternberg Press / laspis.

Mazé, R. (2013). Who is sustainable? Querying the politics of sustainable design practices. In R. Mazé et al (Eds), Share This Book, pp. 83-122. Stockholm: Axl Books.

Mazé, R., and Redström, J. (2009). Difficult Forms: Critical practices of design and research. Research Design Journal, 1 (1), 28-39.

Morrison, A., et al. (2011). Towards Discursive Design, in Proceedings of IASDR, Delft, The Netherlands.

Petrescu, D. (Ed.) (2007). Altering Practices: Feminist politics and poetics of space. London: Routledge.

Practise \& Europa (2009). In M. Ericson et al. (Eds), Iaspis Forum on Design and Critical Practice - The reader pp. 13-64. Berlin: Sternberg Press / laspis.

Prado, L. (2014). Privilege and Oppression: Towards a feminist speculative design. In Proceedings of the Design Research Society DRS conference, Umeå, SE.

Reinfurt, D. (2009). Interview at ExperimentaDesign Biennial, Lisbon, PT. Available at www.design-act.se.

Rendell, J. (2004). Architectural Research and Disciplinarity. Architectural Research Quarterly 8 (2), $141-148$.

Rendell, J. (2005). Architecture-Writing, The Journal of Architecture, 10 (3), 255-264.

Rendell, J. (2007a). How to Take Place (but Not For So Long), in D. Petrescu (Ed.), Altering Practices: Feminist Politics and Poetics of Space, pp. 69-88, London: Routledge.

Rendell, J. (2007b). Critical Spatial Practice: Curating, editing, writing. In J. Rugg \& M. Sedgwig (Eds), Issues in Curating Contemporary Art and Performance, pp. 59-75. London: Intellect.

Rendell, J. (2011). Critical Spatial Practices: Setting Out a Feminist Approach to Some Modes and What Matters in Architecture, in L. A. Brown (Ed), Feminist Practices, pp. 17-56, Farnham, UK: Ashgate.

Schalk, M., Kristiansson, T., and Mazé, R. (Eds.)(2017). Feminist Futures of Spatial Practice. Baunach, DE: Spurbuchverlag.

Schalk, M., Mazé, R., Kristiansson, T., and Fanni, M. (2017). Introduction. In Schalk et al (Eds), Feminist Futures of Spatial Practice, pp. 13-23. Baunach, DE: Spurbuchverlag..

Seago, A., \& Dunne, T. (1999). New Methodologies in Art and Design Research: The object as discourse. Design Issues 15 (2), 11-17.

Stengers, I., \& Despret, V. (2014). Women Who Make a Fuss. Minneapolis, MN: Univocal Publishing.

Tharp, B.M., \& Tharp, S.M. (2013). Discursive Design Basics, Proceedings of the Nordic Design Research Society Conference, Copenhagen, DK.

Yee, J. (2010). Methodological Innovation in Practice-based Design Doctorates. Journal of Research Practice 6 (2), article M15.

About the Author:

Ramia Mazé pursues critical and participatory approaches to design and design research, and she is Professor of New Frontiers in Design at Aalto University. 